\title{
Aplikasi Edukasi Kuis Matematika Untuk Tingkat Sekolah Menengah Pertama Berbasis Android
}

\author{
Yulia ${ }^{1 *}$, Very Karnadi ${ }^{2 *}$ \\ * Teknik Informatika, Universitas Putera Batam \\ yuliaedwar2407@gmail.com 1, very_shredder@yahoo.co.id ${ }^{2}$
}

\begin{tabular}{l} 
Article Info \\
\hline Article history: \\
Received 2019-10-11 \\
Revised 2019-11-07 \\
Accepted 2020-04-20 \\
\hline
\end{tabular}

Keyword:

Education,

Quiz,

Math,

Android.

\begin{abstract}
Mathematics is a science that is widely used in everyday life such as used in trade transactions, carpentry, and so on. But until now many people think that mathematics is a subject that is considered difficult and difficult to understand, especially for junior high school students. Though mathematics itself has been taught starting from the level of childhood and elementary school. Because learning methods still use conventional methods such as the ability to write and count, this is what makes students feel bored because moreover some students do not like these math subjects. Not only in terms of subjects and learning media is still conventional in nature that is only based on the book. For this reason, a learning media is created which is packaged in an android-based application by including elements of mathematics learning in it. The application that was designed was a junior high school level mathematics education quiz application, with the aim of training students 'ability to count, train their memory and increase students' interest in learning in mathematics.
\end{abstract}

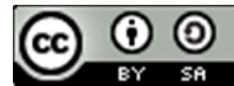

This is an open access article under the CC-BY-SA license.

\section{Pendahuluan}

Perkembangan teknologi informasi yang sangat pesat berupa perkembangan teknologi mobile, beberapa aplikasi mobile telah bermunculan [1]. Dulunya teknologi handphone hanya digunakan sebagai alat komunikasi saja. Seiring dengan perkembangan zaman teknologi mobile saat ini tidak hanya digunakan untuk alat komunikasi saja, tetapi juga digunakan untuk mengakses data, mencari informasi melalui internet, mengirim dokumen elektronik melalui $e$ mail, mendengarkan musik, bermain game dengan cara download aplikasi yang ada, dan lain sebagainya yang dapat digunakan oleh siapa saja, dimana saja, kapan saja secara lebih cepat dan mudah.

Matematika adalah ilmu tentang bilangan dan segala sesuatu yang mencakup segala bentuk prosedur operasional yang digunakan dalam menyelesaikan masalah mengenai bilangan [2]. Matematika merupakan ilmu yang banyak dimanfaatkan dalam kehidupan sehari-hari seperti digunakan dalam transaksi perdagangan, pertukangan, dan lain sebagainya [3]. Hampir setiap aspek kehidupan ilmu matematika yang diterapkan. Namun sampai saat ini banyak yang menganggap bahwa matematika menjadi pelajaran yang dianggap sulit dan susah untuk dipahami. Khususnya pada SMP Negeri 37 Batam. Padahal mata pelajaran matematika itu sendiri sudah diajarkan mulai dari jenjang kanak-kanak hingga Sekolah Dasar. Karena metode pembelajaran masih menggunakan metode konvensional seperti kemampuan menulis dan berhitung, hal inilah yang membuat para siswa merasa bosan karena apalagi sebagian siswa tidak menyukai mata pelajaran matematika tersebut. Tidak dari segi mata pelajaran saja serta media pembelajaran masih bersifat konvensional yang hanya berpedoman pada buku saja. Hal inilah yang menjadi topik dan diperlukan suatu media pembelajaran yang akan manambah minat siswa dalam mata pelajaran matematika. Untuk itu dibuatlah suatu media pembelajaran dengan menggunakan teknologi mobile berbasis android [4]. Media pembelajaran dibuat semenarik mungkin ke dalam sebuah aplikasi agar siswa tertarik dan menyukai mata pelajaran matematika. Siswa dapat mengasah kemampuan dengan menjawab soal-soal yang serta melatih kemampuan dengan soal yang mereka jawab.

Perkembangan teknologi mobile menjadi salah satu perangkat mobile yang saat ini sudah umum digunakan 
adalah telepon seluler. Android adalah sistem operasi untuk telepon seluler yang berbasis Linux. Sejauh ini android termasuk sistem operasi yang cepat sekali memperbarui software mereka [5]. Sebagaian besar siswa sudah banyak menggunakan perangkat mobile tersebut, hal inilah menjadi pemicu untuk memanfaatkan perangkat teknologi dalam dunia pendidikan terutama dalam belajar.

\section{Metode Penelitian}

\section{A. Desain Penelitian}

Desain penelitian memberikan penjelasan dengan menggunakan analisis [6]. Adapun bentuk desain penelitian yang dirancang sebagai berikut.

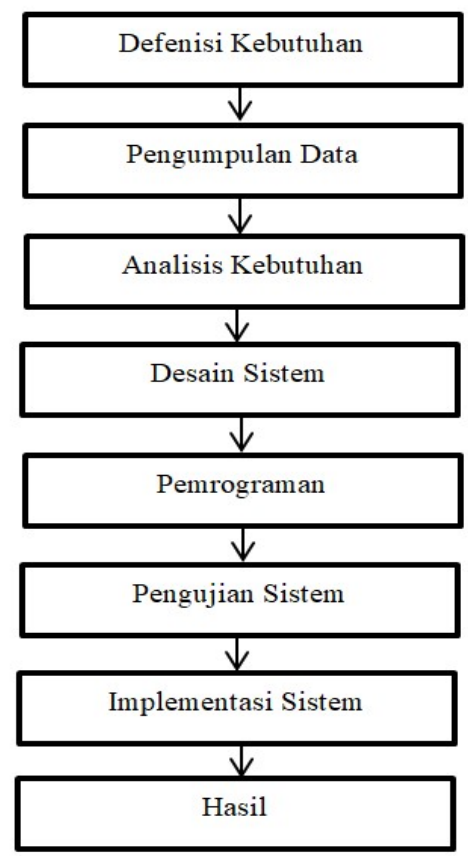

Gambar 1. Desain Penelitian

\section{1) Defenisi Kebutuhan}

Pada tahap ini mengidentifikasi dan mengelompokan permasalahan yang terjadi dalam pembelajaran matematika sehingga dapat dilakukan perancanaan terhadap kebutuhan user agar dapat dilakukan penilaian terhadap kebutuhan baru.

\section{2) Pengumpulan Data}

Pengumpulan data dilakukan dengan cara observasi dan wawancara. Observasi yang dilakukan dengan cara mengumpulkan data dan mencari referensi berupa buku pelajaran matematika yang digunakan oleh siswa SMPN 37 sesuai dengan kurikulum sekolah serta melakukan wawancara dengan guru bidang studi untuk mendapatkan informasi soal-soal dan materi pelajaran yang dibahas di sekolah.

\section{3) Analisis Kebutuhan}

Setelah dilakukan pengumpulan data, tahap selanjutnya dilakukan analisis data. Pada tahap ini mengelompokan materi pelajaran yang akan disajikan dalam bentuk aplikasi. Materi yang akan dibahas yaitu operasi aljabar, fungsi dan persamaan garis lurus, yang akan disajikan dalam bentuk soal-soal objective dan essay dengan tujuan agar memudah user dalam belajar.

\section{4) Desain Sistem}

Pada tahap ini akan dilakukan rancangan sistem kedalam bentuk media pembelajaran yang efektif dan interaktif dari materi yang telah ditentukan sebelumnya. Pada tahap ini diperlukan sketsa desain tampilan layar untuk memudahkan programer dalam menterjemahkan ke dalam bentuk yang lebih nyata. Desain dibuat dalam storyboard untuk mempermudah pengimplementasian perancangan desain.

\section{5) Pemrograman}

Pada tahap pemrograman, perancangan aplikasi menggunakan App Inventor dan Tiny $D b$ dsebagai komponen pendukung yang berfungsi penyimpanan data dalam sistem operasi mobile.

\section{6) Pengujian}

Pada tahap ini akan dilakukan pemeriksaan tombol navigasi apakah ada kesalahan pemberian perintah, navigasi tidak bisa diakses, pengecekan interface, kesalahan pada materi, maupun kesalahan penulisan. Pada tahap ini akan diperiksa satu per satu secara manual dan nantinya akan diperiksa kembali sampai validasi media pembelajaran.

\section{7) Implementasi Sistem}

Setelah tahap pengujian dilakukan, maka perlu dilakukan uji coba terhadap aplikasi, uji coba dilakukan kepada siswa sebanyak 36 orang agar aplikasi yang dirancang dapat digunakan dan sesuai dengan kebutuhan user. Jika terdapat kesalahan maka perlu dilakukan revisi agar aplikasi yang dibangun benar-benar layak sebagai media pembelajaran dan memudah user dalam belajar matematika terutama bagi siswa SMP Negeri 37 Batam.

\section{8) Hasil}

Aplikasi yang dibangun telah dinyatakan efektif setelah dilakukan pengujian, maka aplikasi tersebut layak untuk diterapkan pada siswa SMP Negeri 37 sebagai media pembelajaran matematika yang interaktif berbasis android guna meningkatkan kemampuan siswa dalam belajar khususnya mata pelajaran matematika.

\section{B. Variabel Penelitian}

Operasional variabel yang digunakan dalam edukasi kuis matematika yaiut operasi aljabar, fungsi dan persamaan garis lurus. App Inventor dan TinyDb sebagai komponen pendukung dalam aplikasi dengan sistem operasi android beroperasi pada mobile. 


\section{Hasil dan Pembahasan}

\section{A. Hasil Penelitian}

\section{1) Rancangan Sistem}

Rancangan sistem pada penelitian ini menggunakan bahasa pemodelan Unified Modelling Language (UML). Perancangan use case berdasarkan dari analisis kebutuhan sistem yang akan dibangun. Use case itu sendiri meliputi use case diagram dan user [7]. Use case diagram berfungsi untuk menggambarkan fasiltas yang diberikan aplikasi pembelajaran Matematika untuk user. Use case yang digunakan dalam aplikasi ini antara lain Menu tampilan awal/Home aplikasi yang terdiri dari menu materi berisi contoh soal dan pembahasanya, Choose Quiz terdiri dari Quiz Objective dan Quiz Essay, Aboute dan Exit. Use case diagram yang dirancang dapat dilihat pada gambar berikut.

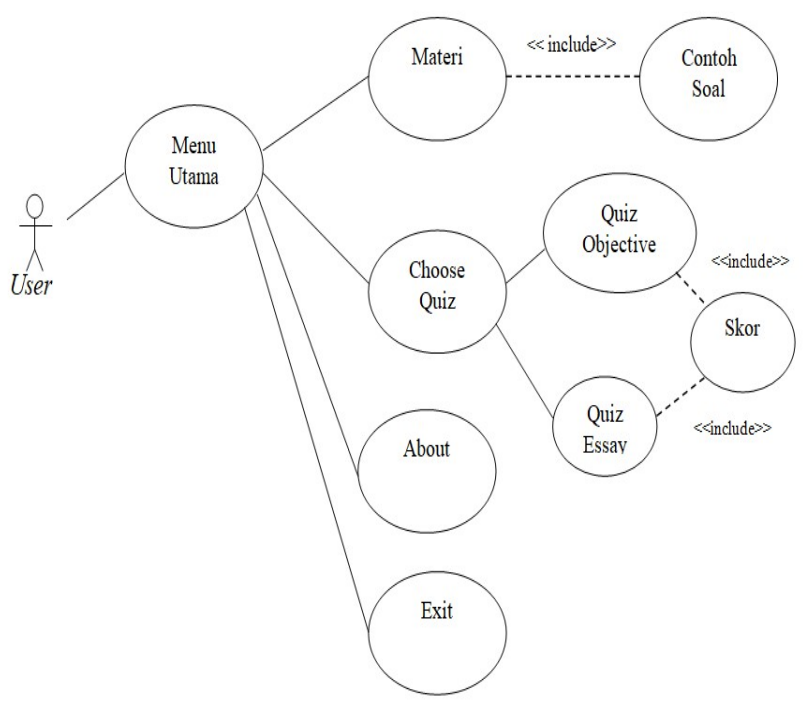

Gambar 2. Use Case Diagram

Gambar 2 Use Case Diagram di atas user dapat masuk ke aplikasi edukasi kuis berbasis android. User di sini adalah orang yang memiliki hak akses untuk masuk ke aplikasi dengan menginstal aplikasi edukasi kuis.

Activity Diagram pada aplikasi ini bermaksud untuk menunjukan urutan aktivitas dalam menjalankan atau mengoprasikan aplikasi. Aktifitas utama yang dilakukan oleh seorang user adalah dengan menginstal aplikasi, kemudian memilih fitur yang diinginkan dan direspon oleh aplikasi untuk memberikan informasi tentang aplikasi [8]. Setelah itu user dapat memilih pilihan yang tersedia pada tampilan awal menu utama seperti menu Materi yang berisi contoh soal, Choose Quiz yang terdiri dari 2 (dua) tipe soal yaitu Quiz Objective dan Quiz Essay berupa latihan soal dengan cara menjawab salah satu opsi yang tersedia dan direspon oleh aplikasi. Beberapa bentuk activity diagram antara user dengan aplikasi sebagai berikut:

Activity Diagram materi menjelaskan tetang bagaimana proses user dengan aplikasi. Dalam hal ini materi yang disajikan berupa beberapa contoh soal beserta pembahasannya. Berikut activity diagram materi terlihat pada gambar 3 .

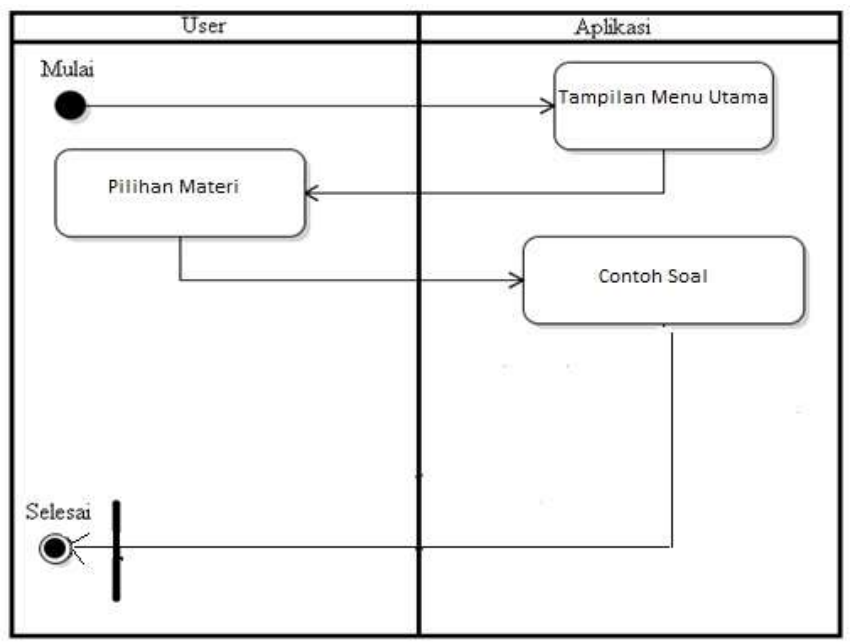

Gambar 3. Activity Diagram Materi

Sequence diagram adalah suatu diagram yang menggambarkan interaksi antar objek dan mengindikasikan komunikasi diantara objek-objek tersebut [9]. Berikut ini adalah gambaran Sequence Diagram antara user dengan aplikasi dapat dilihat pada gambar Sequence Diagram Materi.

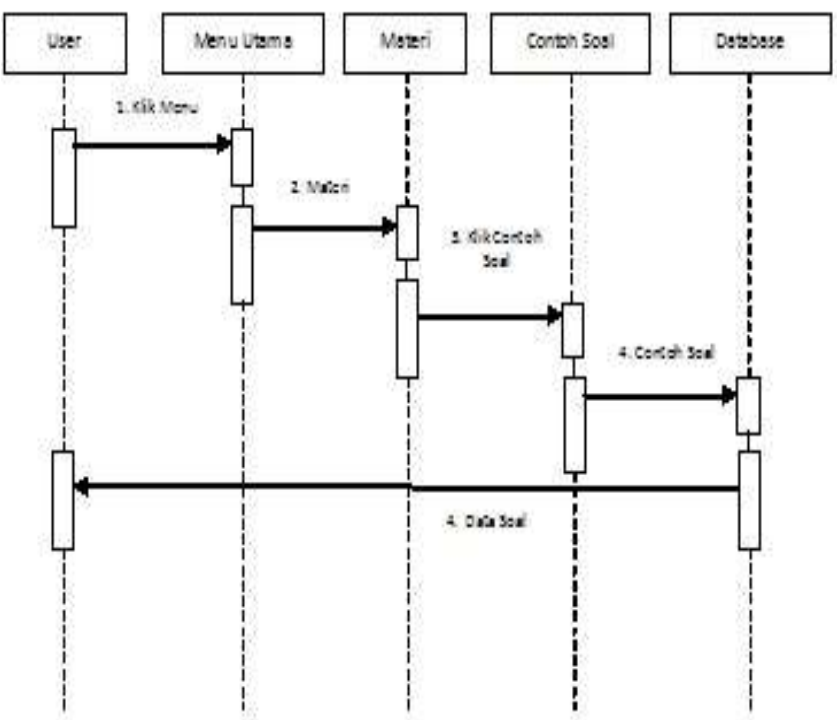

Gambar 4. Sequence Diagram Materi

\section{2) Desain Interface}

Desain Interface bertujuan untuk membuat interaksi pengguna, bagaimana user berinteraksi dengan aplikasi menggunakan tampilan interface yang ada pada layar aplikasi [10]. Berikut adalah tampilan antarmuka aplikasi edukasi matematika sebagai berikut. 
a) Desain Menu Utama

Deain Menu Utama merupakan rancangan awal dalam aplikasi edukasi kuis matematika yang mana terdiri dari empat button dari aplikasi yaitu Materi, Choose Quiz, Aboute dan exit.

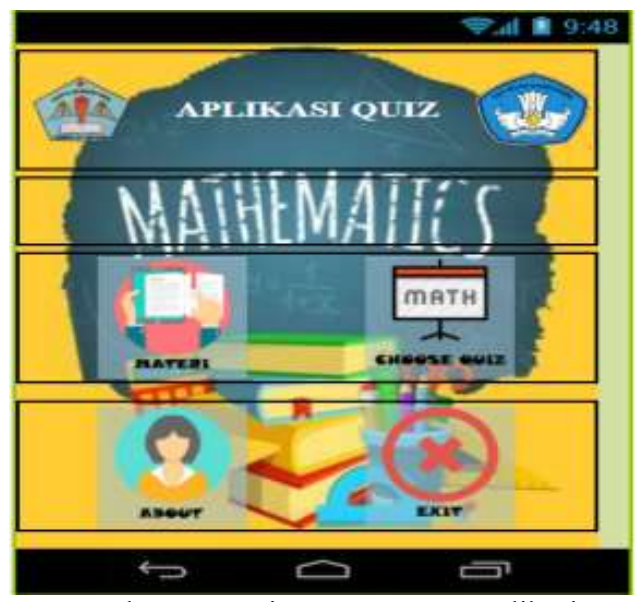

Gambar 5. Desain Menu Utama Aplikasi

b) Desain Materi

Pada desain materi terdiri dari beberapa contoh soal beserta pembahasannya. Desain materi terlihat pada gambar berikut.

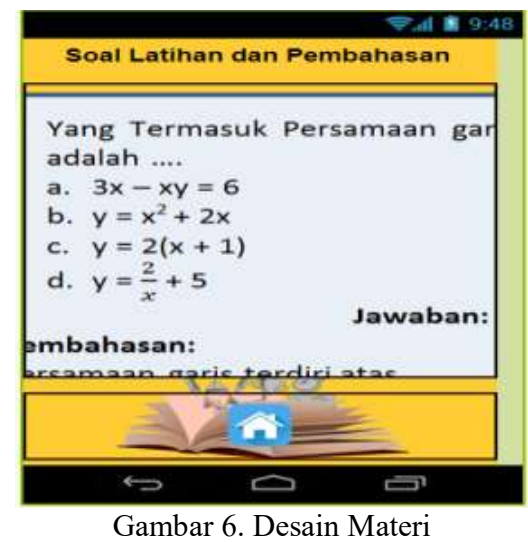

\section{3) Tampilan Hasil Program}

Berikut tampilan hasil program edukasi kuis edukasi matematika.

a) Halaman Utama/Home

Halaman Utama adalah tampilan awal dari edukasi kuis matematika berbasis android ketika pengguna menjalankan aplikasi. Halaman Utama (Home) ini terdiri dari 4 pilihan menu yaitu Materi, Choose Quiz, About dan Exit. Tampilan utama/Home terlihat pada gambar berikut.

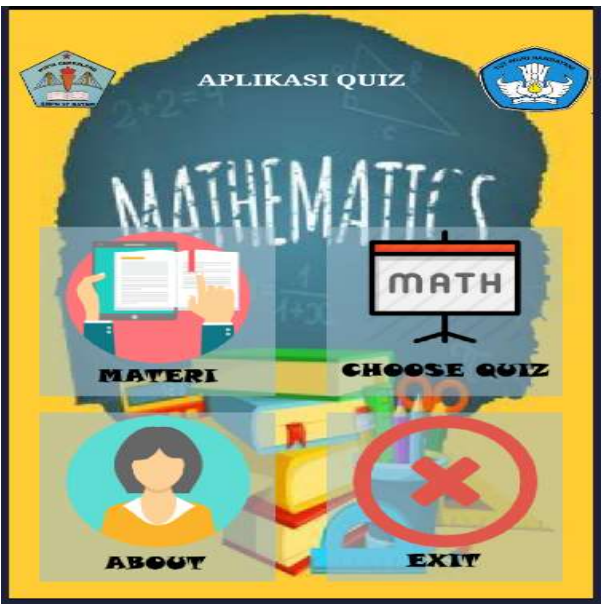

Gambar 7. Halaman Utama (Home)

b) Materi

Materi ini berisi beberapa contoh soal beserta pembahasannya. Materi ini membahas tentang operasi aljabar, fungsi dan persamaan garis lurus. Tampilan materi seperti terlihat pada gambar berikut.

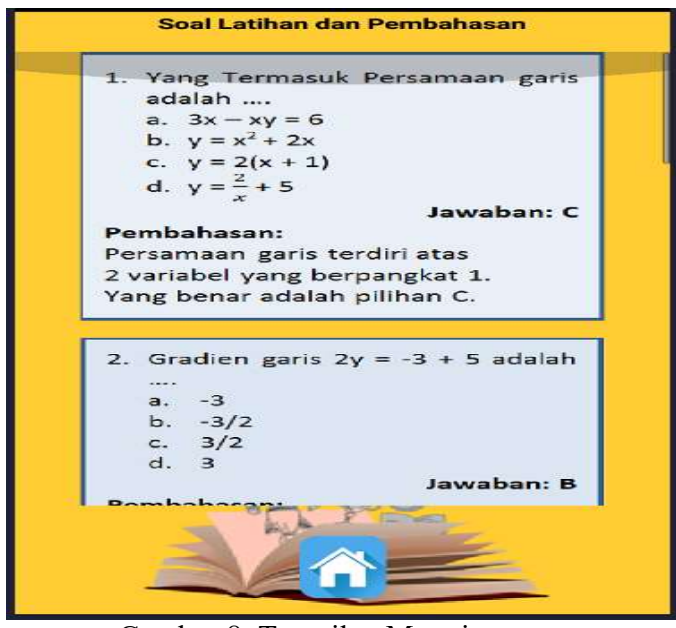

Gambar 8. Tampilan Materi

\section{c) Choose Quiz}

Pada Buttom Choose Quiz, user diminta untuk daftar dengan memasukan nama ke aplikasi. Setelah User mengisikan nama, maka terdapat dua pilihan Quiz yaitu Quiz Objective dan Quiz Essay. Pada tampilan soal Quiz Objective terdiri dari 100 soal, soal dan jawaban bersifat random. Di sini user dapat menemukan soal-soal operasi aljabar, fungsi dan persamaan garis lurus, soal yang akan dijawab oleh user sebanyak 10 soal dengan rentang waktu 20 menit. Soal objective ini terdapat 4 pilihan opsi. Jika jawaban benar maka pada opsi pilihan akan berwarna hijau dan pada Corret akan tertera jumlah jawaban benar, sebaliknya jika jawaban salah akan pilhan opsi akan berwarna merah, pada Wrong akan tertera jumlah jawaban salah. Setiap jawaban yang benar akan mendapatkan 10 
point, dan user akan memperoleh nilai score dari total jawaban yang benar.

Pada Quiz Essay terdiri dari 100 soal, soal yang muncul bersifat random. User akan mendapatkan 10 soal dalam bentuk essay dengan rentang waktu 20 menit. Setiap jawaban yang benar akan bernilai 10 point. User diminta untuk mengisi textbox yang telah disediakan sistem berdasarkan pertanyaan dari soal. Jika jawaban yang diisikan salah maka sistem akan memberikan jawaban benar beserta dengan pembahasanya. Hasil nilai score yang diperoleh tergantung dari jawaban benar.

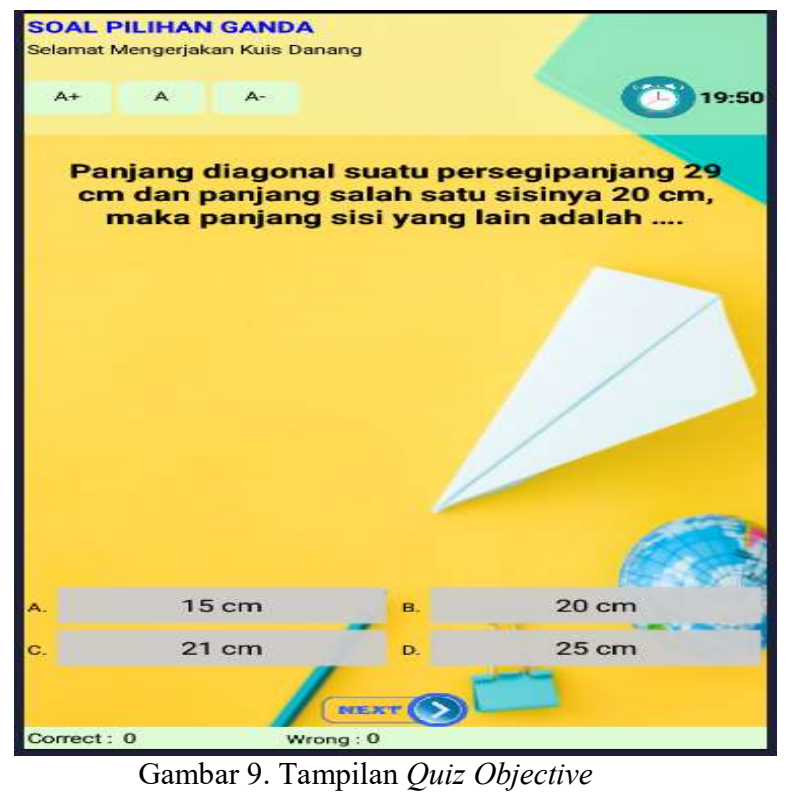

\section{B. Pembahasan}

Aplikasi edukasi kuis matematika yang dibangun user mengintal aplikasi terlebih dahulu. Pada aplikasi terdapat empat menu pilihan yaitu menu Materi, Chose Quiz, About dan Exit. Menu materi berisi pembelajaran matematika yang terdiri dari soal-soal beserta pembahasannya. Soal-soal tersebut membahas tentang operasi aljabar, fungsi dan persamaan garis lurus. Menu Chose Quiz terdiri dari dua pilihan menu yaitu Quis Objective dan Quiz Essay. Pada Quis Objective user akan mendapatkan 10 soal secara random dimana terdapat empat pilihan jawaban opsi yang disediakan aplikasi. User diberi waktu 20 menit untuk menjawab soal-soal yang disediakan sistem dan nilai score yang diperoleh dihitung dari tiap jawaban yang benar dengan nilai 10 point, sedangkan pada Quis Essay user akan mendapatkan 10 soal secara random dengan waktu 20 menit, user menginputkan jawaban yang disediakan sistem, tiap jawaban yang benar akan memperoleh nilai 10 point. Jawaban yang salah sistem akan memberikan jawaban yang benar beserta pembahasannya pada masing-masing kuis. Pada menu About berisi tentang profil pemilik aplikasi. Untuk keluar dari apilkasi user dapat memilih menu Exit. Aplikasi edukasi kuis matematika yang dirancang telah berhasil diimplementasikan dan sesuai dengan kebutuhan user terutama untuk siswa SMPN 37 kota Batam.

\section{KESIMPULAN}

Berdasarkan hasil penelitian dapat disimpulkan bahwa penelitian yang dilakukan berhasil merancang sebuah aplikasi edukasi kuis matematika berbasis android untuk siswa tingkat Sekolah Menengah Pertama sebagai media pembelajaran interaktif, dimana pengguna dapat belajar dan menjawab soal-soal matematika dengan mudah, dapat mengasah kemampuan berhitung dari mata pelajaran matematika serta dapat meningkatkan minat belajar terhadap mata pelajaran matematika.

\section{UCAPAN TERIMA KASIH}

Ucapan terima kasih kepada Universitas Putera Batam atas hibah penelitian internal dalam skema Penelitian Unggulan Program Studi (PUPS).

\section{Daftar Pustaka}

[1] A. Ikwan, M. S. Mauluddin, And Mustagrifin, "Prosiding Snst Ke-8 Tahun 2017 Fakultas Teknik Universitas Wahid Hasyim Semarang 65," Pros. Snst, Pp. 65-69, 2017.

[2] I. Kurniawan, T. D. Tambunan, And I. L. Sardi, "Game Pembelajaran Matematika Untuk Anak Sd Kelas 1 Dan 2 Berbasis Android Menggunakan Construct 2," Vol. 1, No. 3, Pp. 2088-2094, 2015.

[3] Y. Aprilianti, U. Lestari, And C. Iswahyudi, "Aplikasi Mobile Game Edukasi Matematika Berbasis Android Application Of Education Mobile Games For Math Based On Android," Script, Vol. 1, No. 1, Pp. 89-97, 2013.

[4] S. A. Pramuditya And M. S. Noto, "Desain Game Edukasi Berbasis Android Pada Materi Logika Matematika," Vol. 2, No. 2, Pp. 165-179, 2018.

[5] M. N. Jannah And F. N. Hakim, "Rancang Bangun Aplikasi Huruf Hijaiyah Berbasis Android ( Studi Kasus: Taman Baca Al Quran Raziev Reinezhwa Banjarmasin Kalimantan Selatan )," Teknol. Inf. Dan Komuniakasi, Vol. 6, No. 2, Pp. 53-59, 2015.

[6] R. Hartono, A. Purnomo, N. A. Kurdhi, And H. I. Firdiana, "Pembuatan Game Edu Kasi ' English For Fun' Untuk Anak Kelas 1-2 Sd Berbasis Android Menggunakan Unity 3d," Vol. 7, No. 2, Pp. 521-526, 2016.

[7] F. A. Rizal, B. Suyanto, And T. R. Yudantoro, "Aplikasi Game Edukasi Matematika Dengan Konsep Aritmatika Anak," Pp. 45-50.

[8] M. Z. Asghar, K. Nasir, F. M. Kundi, I. Sana, H. Iqbal, And S. Ismail, "Quizzes : Quiz Application Development Using Android-Based Mit App Inventor Platform," Vol. 7, No. 5, Pp. 43-54, 2016.

[9] Y. Amrizal And R. Kurniati, "Game Aritmatika Berbasis Android," Inovtek Polbeng, Vol. 1, No. 2, Pp. 100-104, 2016.

[10] W. Setyaningrum And N. Waryanto, "Developing Mathematics Edutainment Media For Android Based On Students' Understanding And Interest: A Teachers' Review Developing Mathematics Edutainment Media For Android Based On Students' Understanding And Interest : A Teachers' Review," ICMSE2017, pp. 1-6, 2018. 